\title{
Territorial Rights: Concept and Justification
}

\author{
David Miller \\ University of Oxford
}

\begin{abstract}
This paper begins by analysing the idea of territorial rights. It argues that the rights over territory standardly claimed by states can be separated into three main elements: the right of jurisdiction, the right to the territory's resources, and the right to control borders. A full justification of territorial rights must therefore address each of these three elements. It proceeds to examine theories that treat states as the primary holders of territorial rights. Utilitarian theories (such as Sidgwick's) maintain that states acquire such rights simply by maintaining social order over the relevant territory. Such theories are insufficiently discriminating and cannot deal adequately with the issues raised by invasion and secession. An alternative view adds the condition that the state must be the legitimate representative of the people who (innocently) occupy the territory, but this too faces an objection. An historical version of the statist theory would claim that states gain territorial rights by virtue of increasing the value of territory over time, but the paper argues that such historical entitlement theories are especially implausible in the case of states. In consequence it argues that an adequate justificatory theory of territorial rights must treat peoples - standardly, nations - as the primary bearers of these rights. Peoples gain such rights by adding material value to the territory in question, and endowing it with symbolic value. After responding to objections, the paper concludes that such a justificatory theory can unite the three elements of territorial rights distinguished at the outset.
\end{abstract}

In this article, I examine what it means to say that a state holds territorial rights over a part of the earth's surface, and what can justify such rights. I do not try to justify the idea of the territorial state itself. ${ }^{1}$ This is sometimes treated as a conceptual necessity - a state by definition is an entity that wields political authority over a specific territory $^{2}$ - but the question still arises why we should have states defined in this way. Why not instead develop structures of political authority that are not linked to particular geographical sites? This is an important question, but I shall not try to address it here. Even if we are able to offer a convincing defence of the general idea of the territorial state, questions still arise about the nature and extent of the rights over territory that states should possess. And we must also be able to explain how a state can justifiably exercise such rights over a particular area of land - that it needs to possess some territory in order to be a state does not entail that it needs to exercise rights over the geographical area that it now claims as its own.

These questions acquire practical relevance in a number of contexts. The first and most obvious is when territorial rights are disputed between states, or between an existing state and a secessionist group that would like to form a new one. Can the state of Israel make justifiable claims to parts of the West Bank, or does the whole of 
that territory rightfully belong to the Palestinians? Were Scotland to vote to secede from the UK, could this be resisted on the grounds that Scottish territory belongs not just to the Scots but to the British people as a whole? A second set of questions concerns rights to the resources that may be found in any given territory. What justifies the state's claim to own and control these resources? Why should they not be treated as part of the common heritage of mankind, and shared on that basis through some system of redistributive taxation between states? And last but not least, some fundamental questions about immigration and immigration controls cannot be settled without first developing a theory of territorial rights. For any state that asserts the right to exclude would-be immigrants must also assert that such people have no right to enter the territory it claims without its permission, and this would be challenged by anyone who held that the world is initially owned in common by the whole of mankind, so any exclusive territorial claims must require the consent of those who would be excluded.

Such questions form the backdrop to the investigation that follows. Let me note at the very beginning that it is by no means clear that we should regard states as the primary possessors of territorial rights. It may indeed be states that characteristically exercise such rights, but perhaps they exercise them derivatively on behalf of something or somebody else, as a lawyer exercises my rights when he sues someone on my behalf for breach of contract (see also Stilz (2009), p. 190). A natural way to think about territory is to see it as involving a triangular relationship between first, a piece of land, second, a group of people who live on that land, and, third, the political institutions that govern those people in that place. Assume for purposes of argument that there is a justified claim to territorial rights in some place: the question is whether the primary holders of those rights are the people who inhabit the land, or the state (or state-like entity) that governs them. The answer to this question will depend on the justifying theory one adopts, to be investigated later. The important point at this stage is that even if one accepts a territorial definition of the state (such as Weber's), this does not settle the question of whether states get their territorial rights directly, or indirectly as agents of the people they govern.

What, then, are the territorial rights that we normally understand states to be claiming and exercising? We can distinguish three main elements (c.f. Simmons (2001), p. 
306, who distinguishes five elements altogether). The first is what is often called the right of jurisdiction, that is the right to make and enforce law throughout the territory in question. If a state has territorial rights over some area, then anyone physically present in the area in question is subject to that state's legal system and may be punished if he or she violates one of its rules. The second is the right to control and use the resources that are available in the territory. If the territory contains extractable mineral resources, for example, those resources are at the state's disposal to make use of as it sees fit. The third is the right to control the movement of goods and people across the borders of the territory. Recall that at this stage I am simply trying to get clear about what territorial rights actually mean, not about whether they are justified, or what limits may be placed on them. So even if one thinks that states should allow free movement of goods and/or people across their borders, this is consistent with saying that a state that has territorial rights is entitled to control that movement if it so decides.

It might be questioned whether there really are three separate elements here. After all, if a state has the right of jurisdiction, then it has the right to legislate about the use to be made of resources within its territory, and so the second element seems to be contained in the first. Similarly the right of jurisdiction will include the right to make rules governing border-crossings. However even if in a formal sense one could squeeze the three elements into one bag, there are good reasons for not doing so. The right of jurisdiction is primarily a right exercised over persons. It is the right to make rules that require or prevent certain forms of behaviour on the part of persons residing in the territory. The right to the territory's resources, on the other hand, is a right exercised over physical things, and insofar as persons are involved, it is in the first place a right to prevent outsiders from taking or controlling the resources in question. Although it is not a property right, it is akin to a property right in that respect, whereas the right of jurisdiction certainly is not. ${ }^{3}$ Again the right to control borders differs from the latter right, especially when considering its application to those outside the territory. This comes out most clearly when the exercise of the right involves repelling would-be invaders (as opposed to regulating admissions by legal means). A state that defends its territory by fighting against an invading army is not claiming jurisdiction over the invaders, merely the right to exclude them physically from the territory. 
It is not helpful, then, to assimilate all territorial rights to rights of jurisdiction, nor for that matter to regard them all as collective property rights. To do that would be to misunderstand the nature of the rights in question. Moreover the different elements are separable insofar as one could defend a state's right of jurisdiction without defending either its right to the territory's resources or its right to control borders. Suppose, for example, we hold the view that the earth's resources belong collectively to humanity. It would then follow that a state could not claim rights to those resources that lie within its jurisdictional territory unless it did so by mutual agreement (or perhaps satisfied some egalitarian requirement that set limits to the quantity of resources a political community could rightfully hold). In that case a state might have full rights of jurisdiction but be required, say, to pay a global tax for the use it made of the resources in its territory. ${ }^{4}$ Equally it is coherent to say that a state has rights of jurisdiction over everyone physically inside its territory, but no right to decide who should move in or out. The relationship between the three sets of rights should be regarded as an open question at this stage. It must also be an open question whether the same justification can apply to all three kinds of rights, or whether each requires a different kind of grounding.

\section{Statist Theories of Territory}

In order to justify territorial rights, we need first to decide who or what ultimately holds such rights. There are three obvious candidates: individual persons, collectives (groups of persons), or institutions (states). I shall not in this article discuss the first possibility - I have done so (and rejected it) elsewhere (Miller (2011). Theories of this kind hold that individuals can acquire rights of property in pieces of land, and then by pooling such rights create territorial rights over the area in question. By contrast, theories in the second category see territorial rights as arising from the combined actions of groups of people who occupy land, and then as being exercised by states or other institutions that represent them. Theories in the third category attribute territorial rights directly to states (or to state-like entities: here I shall focus on states as the most plausible candidates, under modern conditions, to be the bearers of such rights). My aim is to defend a theory of the second type - specifically a nationalist theory - of territorial rights. But first I want to show why statist theories 
do not succeed, despite the fact that in international law and elsewhere territorial rights are normally attributed to states and only to them.

What form might a statist theory of territorial rights take? In its classic form, for example in Sidgwick, the theory is utilitarian. ${ }^{5}$ States can claim territorial rights by virtue of being able to maintain social order in the territory in question, and thereby promote the well-being of those who occupy the territory. Or as Sidgwick puts it, 'the main justification for the appropriation of territory to governments is that the prevention of mutual mischief among the human beings using it cannot otherwise be adequately secured.' (Sidgwick (1908), p. 252). However even if we accept that maintaining social order at an adequate level is a necessary condition for a state justifiably to claim territorial rights, it is by no means clear that it is sufficient. For there may be alternative arrangements that do the job as well, or better. The territory might be better governed if divided up into several smaller states, or annexed to a larger one. If we follow utilitarian logic to its conclusion, we should have to say that a state can claim territorial rights only if it can show that its performance will be superior to rival claimants, and this opens the door to counterfactuals that will be hard to verify. ${ }^{6}$ Sidgwick himself, when discussing the issues of secession and colonialism, lists the various factors that might tell for and against a particular state's claim to territorial rights, while admitting that weighing these up is unlikely to yield a clear-cut result (Sidgwick (1908), pp. 225-29, 310-28; see also here Hendrix (2008), ch. 6 , sect. V).

What appears to be missing from the utilitarian version of statist theory are considerations that connect a particular state more directly to a particular territory. A possible way forward, therefore, is to impose an additional condition of legitimacy that links the state to the people who occupy the territory in question. This yields a theory that is more Kantian in flavour. It holds that a state has territorial rights when it a) imposes order and administers justice to a sufficiently high standard in the territory in question and b) legitimately represents the people who occupy that territory. This revision seems to take care of the twin problems of colonialism and secession that Sidgwick struggled with: colonialists do not legitimately represent the people they colonise, even if they succeed in establishing an effective state, and secessionists can in appropriate circumstances be justified in claiming that the state 
that presently governs them fails the legitimacy test in their case. Clearly such a theory must appeal to a criterion of legitimacy that is not reducible to effective administration; there must, for example, be some account of authorisation such that one can explain how a state has been authorised to govern by the people who now fall within its jurisdiction (this need not be democratic authorisation, but could take a different form). Let us assume that such an account is forthcoming and focus on the people who the state is going to represent. For it might seem that they must have territorial rights in the first place if the state is going to acquire such rights as their representative. But this would mean that the theory would no longer take the state as the primary possessor of territorial rights, as it seeks to do.

In a recent paper Anna Stilz has attempted to circumvent this problem. She argues that all that must be shown is that the people who the state represents have rights of occupancy - rights to be resident on the land in question - and this is a less demanding requirement than showing that they have territorial rights in the full sense. So when do people have rights of occupancy? According to Stilz:

A person has a right to occupy a territory if (1) he resides there now or has previously done so; (2) legal residence within that territory is fundamental to the integrity of his structure of personal relationships, goals, and pursuits; and (3) his connection to that particular territory was formed through no fault of his own. (Stilz (2011), p. 585)

The last clause is intended to deal with the problem posed by invaders who expel the inhabitants from a territory and set up their own internally legitimate state in that place. The invaders may reside in the place they have occupied and begin to structure their relationships, goals, and pursuits around it, but because that expectation was formed as a result of an unjust course of action - the expulsion of the previous inhabitants who did have rights of occupancy - the third condition is not met and no territorial rights accrue to the invader state.

The problem with this position, however, is that it cannot deal with cases of settlement that appear wrongful even though the individual people involved have not behaved in a way that is morally faulty. This applies, for example, to the offspring of 
the original invaders who are brought up in the new territory and are likely to form the requisite attitudes - so they will gain occupancy rights and the state that represents them will have territorial rights. ${ }^{7}$ It also applies to cases in which ethnic cleansing has occurred. Suppose that at T1 a territory is occupied by two ethnic groups living side by side, and that a militia drawn from one of these groups conducts a terror campaign as a result of which all members of the second ethnic group are forced out of the territory; then at $\mathrm{T} 2$ the territory will be occupied by people most of whom have not been involved in wrongdoing (assume that they gave no active support to the militia), and whose life plans therefore create rights of continued occupancy. What these examples suggest is that a state cannot acquire territorial rights merely by being the legitimate representative of people who, as individuals, have the right to be on that territory: that again may be a necessary condition for territorial rights, but it is not sufficient. It is not sufficient because there may be an alternative state with a better claim waiting in the wings, so to speak - the state that represents the people who suffered the injustice of expulsion.

Both the utilitarian approach to territorial rights favoured by Sidgwick and the more refined Kantian position developed by Stilz are essentially present-oriented, in the sense that they ask whether the state that claims these rights currently meets certain standards of performance and legitimacy. The past does not matter except insofar as it might provide evidence about how a particular state is likely to perform in the future. But this seems to underestimate the relevance of history to territorial rights claims. So might it be possible to construct a theory that remains state-centred but nevertheless is genuinely backward-looking, in the sense that what has happened in the past provides at least part of the grounding for territorial rights? Such an attempt is made by Cara Nine when she argues that 'on a Lockean theory of desert claims to land, states can come to deserve territorial rights to land' ${ }^{8}$ How plausible is it to attribute such desert claims to states?

There is some ambiguity in Nine's discussion about the relationship between state and people - i.e. between the state as a formal institution that exercises power and authority and the people who fall within its jurisdiction. She says, for example that 'the state can be seen as (at least in part) the manifestation of the coordinated efforts of individual members of the state. Much of the value of the lands occupied by the 
members of the state is due to the coordinated efforts of those members.' (Nine (2008), pp. 159-60). This ambiguity is unfortunate if one wants to determine whether territorial rights belong primarily to states or to peoples. So let us consider the argument as applied to the state strictly understood. The claim is that the state has, through its past actions, contributed to the value of the land that it governs, by, for example, legislating to create 'stable systems of agriculture' and shaping the appearance of the landscape through zoning laws. Accepting this factual claim, it is difficult to make sense of the idea that a present-day state deserves the value created as a result of the actions taken by that same state in the past. Indeed it is hard to make sense of the idea of institutions having deserts at all, unless this can be cashed out in terms of the deserts of the existing members. Thus one might say that a football team that has played well all season deserves to be promoted to the division above, but this can be translated into a claim about the deserts of the members of the team. But to say that, for example, Oxford United today deserves something on the basis of what Oxford United did 50 years ago does not make sense, given the complete change of personnel between now and then. It is important here, as always, not to confuse desert and entitlement. Institutions can transmit entitlement across time under appropriate conditions. If the UK football league had a fixed membership (as the National Football League in the US now does) Oxford United might be entitled to a place in it by virtue of a decision made 50 years ago. So could we translate Nine's argument into a claim about historic entitlement? The argument would be that a state that has once established territorial rights - say by engaging in the value-creating activities that Nine describes - is then entitled to enjoy those rights in perpetuity, so long as it in some relevant sense remains the same state.

Such an argument is conceptually coherent, but lacks persuasive force. It suffers from the general weakness of historical entitlement theories, that they are insensitive to changing circumstances that may undermine the basis of the original entitlement. It is not clear why a state whose claim to rule a territory in 1600, say, was justified by the criteria of performance and legitimacy that were appropriate at that time should continue to have territorial rights by virtue of that historical fact. Criteria of legitimacy may change (for instance a theocratic state may lose legitimacy as the society it governs becomes more secular) or minority groups within the society may begin to issue self-determination claims that the state is unwilling to grant. So even if 
we bolster the historical entitlement condition with Sidgwick's condition that the state in question must now exercise 'a tolerably effective and continuous governmental control over the territory in question', it is still not clear that we have a sufficient justification for the state's present exercise of territorial rights.

\section{Nationalist Theories of Territory}

The review of statist theories in the previous section suggests that it is a mistake to treat states as the primary holders of territorial rights. The justifying arguments that appeal to standards of performance and legitimacy in the present may succeed in identifying necessary conditions for states to have such rights, but they are not discriminating enough - they award such rights too easily to usurper states. A backward-looking argument that awarded a state territorial rights on the basis of its past performance would be sufficiently discriminating, but as we have just seen such an argument lacks persuasive force. So let us now turn to the alternative approach, which sees these rights as belonging in the first place to peoples. A state's claim to exercise territorial rights can then be understood by treating it as the legitimate representative of the people in question. A successful theory of this kind must achieve three things. First, it must explain what makes a group of people into the kind of collective that is capable of having territorial rights. Second, it must explain what exactly it is that connects the group in question to the territory it claims in a way that has ethical force - if the claim is that territorial rights follow from the group having done such-and such, why is this a matter of justice, for example? Third, it must show why territorial rights, in the full sense explained in section I above, are justified on this basis, rather than some lesser entitlement such as, for instance, rights of continued occupancy. This is quite a demanding schedule.

The first question arises because we are trying to establish collective rights proper rather than an aggregate of individual rights. Moreover, since territorial rights must be reasonably stable, these collective rights must endure across generations. So we need to find a transhistorical agent that can be the bearer of such rights, without relying on the state to perform this role (since we are now treating state claims to territory as derivative). A group that fits this bill must be one whose identity is such that it can be transmitted across time, with newly-arriving members being bound to the existing ones through an inherited understanding of the nature of the group. It 
could not, in other words, be a group that is formed simply by mutual co-operation: such a group might be able to generate collective rights for its existing membership, but those rights could not be transmitted forward in time to a later group that cooperates in the same way. ${ }^{9}$ So what kind of group could count for this purpose? The most plausible candidates are nations and indigenous peoples, collectives that share certain features such as common identity and a shared social of social rules, but differ in other ways. ${ }^{10}$ These groups have the appropriate transhistorical character, and are also able to relate to land in ways that, as we shall shortly see, can justify the ascription of territorial rights: indeed some of the most intractable disputes over territory arise when modern nations and aboriginal groups make rival claims to the same piece of territory. ${ }^{11}$

Moving now to the second issue, what must groups of these kinds do to establish territorial rights? It seems clear that simply taking possession of territory (e.g. by conquest) is not sufficient, venerable though this idea undoubtedly is. To establish a transformative relationship to land of the kind that can give rise to such rights requires long occupation. Typically there will be both material and symbolic transformation in varying proportions. That is, the land has its material value enhanced, by cultivation, for example, or by the creation of buildings, roads, waterways and so forth. At the same time, particular places, or areas within the territory, acquire symbolic significance for the group. In some cases this will happen as a result of specific events in the history of the group occurring on the territory, so a field becomes the place where a battle was fought or a building the place where an historic document was signed; in other cases it will be more a question of rituals and practices that endure over long periods of time and mark out built sites or natural features as 'sacred' to the group (for a good description of this process, and some relevant examples, see Smith (1999)). As a result of occupation and transformation, therefore, the territory becomes a repository of value for the people in question. It is materially valuable because it has been improved in a way that reflects their needs and cultural values, and it is symbolically valuable because of the meaning that members of the group now attach to particular features of the land in question. Moreover this value is something that can only be enjoyed by the group so long as it remains in possession of the territory. 
Let me look in a little more detail at this argument and consider some possible objections to it. As I have presented it, it weaves together three different claims. The first is a backward-looking claim about the creation of material value, which might be described as quasi-Lockean in character: it holds that groups are entitled to keep and enjoy the value they have created historically. The second is again a material claim, but this time a present- and future-oriented one: it says that the territory has been shaped to fit the needs and the cultural values of the group in question, so if it is now taken from them, they will no longer be able to sustain their way of life. The third claim is non-material: it points to the internal relationship between the group's culture and its territory and claims that losing the territory would be to lose much that is of symbolic value to the group, and therefore essential to its continuing identity as a people. Note that if the argument for territorial rights is to succeed, these claims must be understood in such a way that those outside the group as well as those inside have reason to accept them. ${ }^{12}$

The first of these claims appeals to a standard of value - the group is said to have enhanced the territory it occupies - and it is therefore open to the objection that in a culturally plural world there is no agreed standard of value to which such appeal can be made. In particular, it has been argued that the material value argument contains an inbuilt bias in favour of modern nations, who have transformed land in such a way as to increase its economic value conventionally defined, and against indigenous groups whose activities may have more to with sustaining the ecological value of the land they inhabit. There is no doubt that historically what I have called the quasiLockean argument has been used for this purpose, specifically to justify the displacement of indigenous groups by 'productive' colonisers (for an example, see Moore (1998), pp. 147-8). But it need not be understood in this way. It is not a maximising argument: it does not say that land should go to whichever group is able to use it most productively by some standard. ${ }^{13}$ It says only that when a group has interacted with land in such a way as to increase its value, this gives the group a prima facie right to hold the land so as to be able to enjoy the enhanced value - to reap the fruits of cultivated land or to travel down the roads they have built.

It is still necessary, however, that we should be able to identify an increase in value. Here it may be useful to distinguish between what we may call universal value and 
culturally-specific value. The idea of universal value depends on the assumption that there are certain conditions necessary for the achievement of a decent human life in any society - in other words that there are basic needs that all human beings have in common. ${ }^{14}$ If this assumption is granted, then we can say that any change that increases a society's capacity to fulfil these conditions over time adds universal value. Obvious examples would include cultivating land to produce essential foods, digging wells to find clean water, draining malarial swamps, building roads and bridges to increase the mobility of people in isolated communities, and so forth. These activities are valuable according to a standard rooted in the very idea of a decent human life, and this cannot be reasonably be denied no matter to which cultural group the interlocutor belongs.

Culturally-specific value, by contrast, and as its name suggests, refers to outcomes that are valuable only from within a particular worldview, and which can therefore be seen as having no value, or even negative value, by those who do not share that outlook. Obvious examples here would be building churches and planting vineyards, activities whose value depends on a view about the significance of the Christian religion on the one hand and the consumption of alcohol on the other. Clearly many claims made by nations today about their value-enhancing activities appeal to such a culturally specific understanding of value, and this explains why indigenous groups, in contrast, are often at pains to deny that the land that has been taken from then by colonisers and 'improved' has actually been improved by the standards they recognize.

The distinction having been drawn, it should be clear that the material value argument is most persuasive in cases where the group that occupies a piece of land adds universal value to it, by for example, increasing the fertility of the soil and thereby making it more productive. However I want to argue that groups' territorial rights can also be justified by the adding of culturally specific value provided that universal value is not diminished by the groups' activities. That is to say, groups that lay waste to land in the pursuit of some culturally specific project don't deserve territorial rights, whereas groups that simply add cultural value but without reducing universal value can claim such rights, as a way of capturing the value they have added. By 
preserving universal value they have done enough, under normal circumstances, to defeat the claims of outsiders who might otherwise wish to use the land. ${ }^{15}$

Without suggesting that this resolves all of the problems with the material value argument (many of which will have to do with empirical questions such as whether a group's practices do actually add (universal) value to land over the long term), let me consider a second objection which asks how later generations who inherit land can claims rights to territory that they have not themselves improved. One problem with this objection is that peoples cannot be sorted into discrete generations such that one could say that this generation created these objects of value and not those. Of course, in the case of any individual, one can say that at the moment at which he becomes capable of contributing value there are certain pre-existing historical achievements for which he can take no credit. But this person will then co-operate with a constantly changing set of contemporaries (as others enter and leave the category of contributors) such that whatever value is created over his lifespan is attributable to a very large number of instantiations of the collective. One cannot then individualise the value in such a way that this person only enjoys the portion for which he was responsible. ${ }^{16}$

This reply may weaken the force of the objection without entirely rebutting it. It shows what is wrong with the idea that there are distinct generations each of which is only entitled to enjoy the added value that they have created themselves. But it may still be thought that if we claim territorial rights on the grounds of being entitled to benefit from the value that our predecessors have created, it is just a matter of luck that we inherit the land from predecessors who have added value in this way. Here, however, the second strand of the material value argument comes to the rescue of the first. Since land has been shaped in a way that reflects the group's distinctive culture, continued occupancy of that land becomes essential if the group is to live a flourishing life. Of course group cultures are not rigid. A displaced group forced to make a life in a new place will eventually adapt and find ways to survive. But one should not underestimate the human cost that this imposes. So although living on historically improved land is in one sense an undeserved benefit, being excluded from that land is certainly an undeserved loss. 
Someone committed to a principle of global equality of resources might still argue here in favour of taxing historically advantaged groups for the enhanced value they enjoy while leaving them in control of the land itself. If value is to include both universal and culturally-specific value, however, we face the problem of finding a metric by which different forms of value can be commensurated - a task that, as I have argued elsewhere (Miller (2007), ch.3), is likely to prove impossible to discharge.

A different objection to the argument from enhanced material value is that it is effectively redundant, because adding value to a place only gives you a claim to retain that value if you are already legitimately entitled to occupy that place. In other words, I cannot by sowing corn in your field establish a claim to that field, even if that is the only way for me to reap what I have sown. So the value-adding argument only applies to nations that have already established their rights to the territory within which the value is created, and it therefore presupposes some other account of territorial acquisition.

This objection also is less weighty than might at first appear. It certainly shows that a nation cannot gain territorial rights simply by displacing another people and then undertaking some value-creating activities in the place in question. But maybe all that is needed initially is a liberty to occupy territory - the absence of a countervailing duty. Suppose for example that a group of colonists sets sail for an uninhabited island. Initially they have no better claim to that territory than anybody else. But if the value-enhancing argument holds, they may gain territorial rights by cultivating the ground and so forth. Or perhaps there is no clear answer to the question which group originally holds title to a piece of land. In that case the group that occupies the land and improves it over time may come to have territorial rights. The value-enhancing argument fails only where another group is clearly being wronged by being excluded from the territory at issue. ${ }^{17}$

I turn next to the argument about symbolic value, which holds that groups can claim territorial rights by virtue of the meaning that particular pieces of territory have come to possess for the nation or indigenous group in question. What are the objections to this argument? One is that the creation of symbolic value in a particular place seems 
not always to give rise to territorial claims. We can see this by thinking of colonial nations, where some part of the national story may involve events that took place in the former colonies - for British people the Black Hole of Calcutta or the Relief of Mafeking, say - without it following that the nations in question either do or should assert any territorial rights to those places today. But what this shows is that the symbolic value argument presupposes an idea of the nation's homeland: it is events that occur on that homeland that generate ongoing territorial claims. In the case of events occurring outside of that setting, all that matters is that nationals should be granted access to these significant sites, or that they should be marked and respected in some way (in the case of war graves, for example).

I should make it clear that 'homeland' here means the territory that the group in question takes to be its own, which may or may not correspond to the land that it now holds. So symbolic value claims are not innocuous: they can give rise to fierce conflicts whenever the site in question is currently held by a rival group. A wellknown example is Kosovo, which contains the battlefield site of Gazimestan where in 1389 the Serbian Prince Lazar fought against the invading Turks - an event that now marks the most important day in the Serbian national calendar. ${ }^{18}$ For Serbs, the land of Kosovo remains part of Serbia proper: an independent (or Albanian) Kosovo cuts them off from part of their national history. Their claim is not merely one of prior occupancy but of the symbolic importance of the events that occurred in that place.

This example may, however, serve to introduce the more general objection to the symbolic value argument. It appears to make territorial claims too dependent on the subjective imagination of national communities. We know that national histories typically contain a significant proportion of myth: even if historical events are not wholly invented, they are nevertheless described and interpreted in ways that may depart considerably from the findings of impartial historians. How can a justifiable territorial claim rest upon what may seem to be a false or irrational belief about some past occurrence in the nation's history?

I have tried elsewhere to mount a defence of national myths as performing, under the right conditions, the important functions of strengthening national solidarity and influencing present-day behaviour by serving as moral examples of what the nation, at 
its best, is capable of achieving (Miller (1995), ch. 2, sects IV-V). As part of that defence, I claimed that national identities formed under conditions of relatively open dialogue between different sub-groups within the nation were unlikely to include blatant historical falsehoods. So in these cases at least, the value that is attached to particular places on account of their historical significance is unlikely to be purely imaginary. Nevertheless we should be aware that symbolic value claims can be open to manipulation by groups, perhaps not representative of the nation as a whole, who see it as in their interest to insist on the special significance of a particular site or area of land and therefore seek to distort the historical record for that purpose.

Symbolic value arguments are most powerful when advanced by groups who presently occupy the territory to which the arguments apply, and who can therefore point to continuities in their practices and cultural understandings that rely upon having access to the sites in question. ${ }^{19}$ It might then seem that such arguments are superfluous, because when put forward by present occupants they merely supplement the material value arguments discussed above, while if advanced by those who do not currently hold the territory that they claim to be symbolically significant, it is unlikely that they will defeat the rival value-claims (material and/or symbolic) of those now in possession. Yet I believe a theory of territorial rights needs to include the symbolic value argument if it is to deal in an even-handed way with the territorial claims of peoples of different kinds. Relying simply on the material value argument would indeed bias the theory towards groups that look like developed Western nations. It has often been pointed out that indigenous people may relate to their land in a different way - they may change it little or not at all in physical terms, but they may endow it with a great deal of symbolic meaning. To do justice to their claims, we need a theory that combines the two arguments, and allows material and symbolic value claims to be balanced against one another.

\section{Jurisdiction, Resources and Border Controls}

That concludes my discussion of the grounds on which groups can claim territorial rights. But it might seem that the arguments I have canvassed, even if successful in their own terms, justify something much less than states' territorial rights as set out in section I. In particular, it may appear all that follows, from either the material value argument or the symbolic value argument, is a right to territorial occupancy. A group 
that has created material value that is now physically embodied in a certain territory needs to live on that territory to capture it; equally, if a place is rich with symbolic meaning, the group must actually be there to enjoy it. But this does not entail having a state with the three kinds of territorial rights that I distinguished earlier - rights of jurisdiction, rights to resources, and rights to control borders.

One reason for concern is the geographical scope of the rights that states now assert, which often extend well beyond the territory that the peoples they represent have transformed. They typically include mountainous or desert regions that have been left uncultivated, for example. And even where these natural landscapes take on symbolic significance, this does not usually determine where the borders should be set. The Alps matter greatly to Swiss national identity, for example, but this does not help us decide whether a particular mountain should be Swiss territory rather than Italian or French.

It should be conceded in reply that a considerable degree of historical contingency enters into the precise placing of state boundaries. This should not disturb us so long as we continue to accept the general justifying argument for the territorial state. It belongs to that argument that state boundaries should be clear, continuous and in normal cases reasonably straight for reasons of efficiency. A state can then be justified in asserting territorial rights on behalf of the group that occupies an area of land, provided that the group has transformed most of that land in one or other of the ways described above, and provided there are no rival claims to parts of it that could be recognized by redrawing borders.

How does the argument advanced in section III justify the three specific rights to territory distinguished in section I? Rights of jurisdiction are relatively easy to defend. If a group has added value to territory, its continued enjoyment of the value it has created will always be insecure unless the territory is controlled by political institutions that represent the group. Rights of private property alone will not serve because a) such rights are always susceptible to being redrawn by whoever holds rights of jurisdiction and b) much of the embodied value that the group has created is likely to be located in public space - in public architecture, landscapes of historic significance, and so forth. The group needs to maintain overall control over the 
territory in order to secure that value over time, and for that it needs rights of jurisdiction such as those normally exercised by a state. Note, however, that this does not translate straightforwardly into a claim for sovereignty, because of the possibility of groups with overlapping claims - for instance the case where an encompassing nation includes national minorities with their own distinct histories, where rights of jurisdiction should be divided up in a way that reflects the competing claims at stake, for instance through a federal constitution.

If we now turn to consider the right to the territory's resources, it may not be so clear how occupying and transforming land gives a group a right to the land itself, including the minerals and so forth that were present in it all along, rather than merely to the increased value that the group has created. So although the group may be able to claim that it must stay on the land to enjoy that value, why shouldn't it be taxed on the basis of the natural value of the land it occupies, the proceeds being paid into a fund for global redistribution? ${ }^{20}$ Such a proposal may be supported by appealing to the idea of equal original ownership of the earth. The main difficulty it confronts is to find a meaningful way of disentangling natural land values from the value of land as it is affected by human activity - not only the labour of past generations in transforming the land, but the readiness of the present generation to use the land in certain ways (for example to cluster together in cities and creative complex networks of cooperation that largely explain the very high purchase and rental values of inner-city property). ${ }^{21}$ The proposal has greater intuitive plausibility in the case of mineral resources such as oil and diamonds. But here it is possible to be held captive by a certain picture of the way these resources are extracted and used - that is, one imagines them being whisked out of the territory and sold at the world market price, creating a pure windfall gain for the society in question. In reality the extraction process may have quite profound effects on other features of the society, not only its employment structure and level of development but also the kind of political system that it is able to support - effects that have been well documented in the literature on so-called 'Dutch disease' or 'the resource curse' (for an accessible overview, see Wenar (2008)). This means that the real value of having, say, reserves of oil to the society that has them cannot be estimated simply by calculating the volume of extractable oil and multiplying by the market price net of extraction costs. A realistic 
assessment must consider the actual impact - negative or positive - that extracting and selling the oil would have on the society in question.

These considerations are I believe sufficient to undermine proposals for a global egalitarian redistribution of the value of natural resource holdings. ${ }^{22}$ Yet they do not by themselves establish positively that the group that can claim jurisdiction over a piece of territory should also hold the resource rights to that territory. The story we tell to explain why the Norwegians have jurisdictional rights in the land of Norway does not directly justify their having the right to the oil they extract from that territory. The argument has to be more indirect. On the one hand because of the way that the availability of natural resources influences the general course of the society's development, for reasons of self-determination it will normally be desirable that the resources should remain under the collective control of the society's members. On the other hand, as Rawls has emphasized, giving peoples responsibility for the resources that lie within their territory encourages them to use those resources in a sustainable way, so as to support their way of life in perpetuity (Rawls (1999), sect. 4.3). This of course assumes that the groups in question have transhistorical identities in the sense explained above, such that the present generation that has inherited rights from its predecessors recognizes reciprocal obligations towards successor generations stretching far into the future.

Finally there is the contested question of the right to control borders. This has several aspects, but I shall focus on the right to exclude those who are not already members of the group that holds jurisdictional and resource rights. What can justify this, in the face of what are sometimes urgent humanitarian claims to be admitted? Why should it matter who is physically present on the territory in question if the other rights are securely held?

It matters for two reasons, one having directly to do with physical presence, the other having to do with citizenship, if we assume, as I do, that people who are admitted to territory on a permanent basis, are entitled in due course to become full citizens of the state that governs it. Take physical presence first. We are working with the idea of a people who have transformed territory historically, continue to occupy it, and have a deep interest in the territory as repository of their cultural values. It matters first how 
many people are on the territory at any time. If there are too few, it may be impossible to maintain historic buildings or landscapes of historical significance - for example upland areas may revert to forest if not grazed by the animals of hill farmers. If there are too many, it may become impossible for land to be used in the way that the group's values require, as pressure for new housing, roads, and commercial development mounts. This can apply even in the case of those who visit on a short term basis as tourists, where sites that are ecologically sensitive or have a religious significance may be damaged as increasing numbers of people choose to visit them. ${ }^{23}$ For the same reason, it matters who the people are that are present on territory whether their use of land will be such as to add further material or cultural value, maintain it, or subtract from it.

These considerations are not meant to be directly prescriptive. It will often be hard to decide what the impact of admitting particular groups of people to territory will be, and also whether, even if the impact is thought to be negative on balance, this is outweighed by threats to the human rights of those seeking admission. The argument establishes only that the group that legitimately controls territory, whether a nation or an indigenous people, should have the right to decide who has the right to enter. - it does not determine which exercises of that right are justified and which are not.

Admission decisions will also change, over time, the composition of the body that exercises territorial rights - the body of citizens in the case of a democratic state. When immigrants become full citizens of such a state, this means more than that they should formally have an equal opportunity to participate in democratic procedures. It also means that when public policy is being decided, say over which public goods are to be funded out of state revenues, their claims must be given equal weight with those of native-born citizens. ${ }^{24}$ This has implications for the future shaping of territory. We can perhaps see this most clearly if we think of an indigenous people whose territory has been deeply imprinted by a pattern of land use that reflects their common culture. Suppose now that newcomers with very different ideas about the significance and proper use of land enter the territory, and are integrated on terms of equality. Future decisions about land use, for example decisions about the kind of regulation that should apply to privately-held land, must then represent a fair compromise between the two sets of cultural values. Members of the indigenous group are likely to 
experience this as a significant loss of control. So they have reason to prevent the newcomers from taking up residence in the first place.

So, to sum up, conceptually speaking we can divide territorial rights into rights of jurisdiction, rights to resources and rights to control borders. But if, as I have argued, such rights belong in the first place to peoples and not to the states that represent them, and if such rights are justified not by the mere fact of occupancy, but by the material and symbolic value that becomes embedded in territory with the passage of time, then we can see why such rights will normally belong together. A group, typically a nation or an indigenous people, that gains rights of jurisdiction over land on the basis of the value embodied in that land will also have a good claim to control the resources the land provides and to decide who should have access to it, either temporarily or permanently. These latter claims are subject to certain limits, especially those imposed by the human rights of outsiders. Just as necessity may trump the right to private property, so it may trump the right to territory. But with that important qualification, the idea that states may claim and exercise the full set of territorial rights as representatives of the peoples they govern appears sound.

\section{Notes}

Earlier versions of this paper were presented to the workshop on Theories of Territory: Justice, Resource Rights, Self-Determination and Immigration, London, February 21-22, 2009, to the conference on Extensions of Justice, Hebrew University, Jerusalem, June 3-4, 2009, to the political theory seminar, University College, London, October 28, 2009, to the Nuffield Political Theory Workshop, November 2, 2009, and to the workshop on Territorial Rights, Queen's University, Ontario, June 45, 2010. I should like to thank the participants in all of those meetings for their helpful comments, and especially Chaim Gans, Annie Stilz and Bas Van der Vossen who acted as interlocutors on the first two occasions. Further thanks are due to the anonymous referees for this journal for their extensive critical suggestions.

${ }^{1}$ For a very interesting exploration of the history of this idea, see Baldwin (1992).

${ }^{2}$ See, for example, Weber's famous definition: ' ...... a state is a human community that (successfully) claims the monopoly of the legitimate use of physical force within a given territory. Note that "territory" is one of the characteristics of the state.' (Weber (1970), p. 78.) 
${ }^{3}$ It is not a property right because it is a right that the state will use to determine property rights by, for example, establishing rules to govern landholding by private individuals, or granting extraction rights to mining companies. It is often argued that to see territorial rights as (collective) property rights involves a category mistake, and for the reason just given this is true. On the other hand, any discussion of territorial rights must be alive to the fact that territory is not just a place where jurisdiction is exercised but also a multifaceted resource - which is why such rights are often contested, and why they may raise issues of distributive justice. For a fuller discussion of the distinction between property rights and territorial rights, see Miller (2011), and also Hendrix (2008), ch. 4.

${ }^{4}$ For a proposal of this kind, see for example Pogge (1994), 195-224. I am not here endorsing Pogge's Global Resources Tax, merely pointing out that it is compatible with states enjoying full rights of jurisdiction within their territories.

${ }^{5}$ See Sidgwick (1908), chs. 24-25. A more recent statist theory, that takes the protection of basic human rights as the grounding value that confers legitimacy on a territorial state, can be found in Buchanan (2004). For a critique of Buchanan, see Kolers (2009), pp. 40-46.

${ }^{6}$ Others have discussed efficiency arguments for territorial rights that focus on the efficient use of land: see Moore (1998); Meisels (2009), ch. 6; Nine (2008).

${ }^{7}$ Stilz argues that those who have been unjustly expelled, and have not established full citizenship rights in some other place, have the right to be readmitted to their former territory and be given equal citizenship rights there, though not to push the invading group out. But is this good enough? Suppose those who return now form a minority in a state dominated by the invaders. They may have equal rights of citizenship, but they cannot control the way that the territory now develops. There is a sense in which they have lost the territory even though they are physically present in it. It is hard to see that the invader state is justified in claiming territorial rights in these circumstances

${ }^{8}$ Nine (2008), p. 159. I am focussing here on just one of the three arguments that Nine uses to develop her theory of territorial rights. The other arguments, appealing to liberty and efficiency, are present-oriented rather than backward-looking.

${ }^{9}$ Think, for example, of a football club that decides to play in a public park, marking out and tending pitches with the consent of the local authority. We will think that the club gets some (fairly weak) rights over the terrain it has adopted. These rights will survive changes in the club's membership. Suppose now that the club dissolves and some time later another club is formed, which claims the right to play football in the same place. It seems clear that this club has no such right even though it is engaging in the same co-operative practice as the first club. What is missing is an identifying link between the members of the first club and the second.

${ }^{10}$ I have indicated what I take to be the characteristic features that distinguish nations from other social groups in Miller (1995), ch. 2. For the idea of nations as collective agents, see Miller (2007), ch. 5. 
${ }^{11}$ I leave it an open question whether the territorial claims of indigenous peoples are best understood as claims for (full) territorial rights as I have defined them. For thoughtful discussion of how modern liberal societies might accommodate these claims, see, for example, Levy (2000), ch. 7; Ivison (2002), ch. 7; Hendrix, (2008), ch. 8 .

${ }^{12}$ Why should outsiders give any weight to claims that appeal to the cultural values of a specific group? The answer must be that everyone can recognize the human need for cultural integrity - meaning here not having one's culture involuntarily destroyed or transformed by outside forces - without subscribing to any particular set of cultural values. For example, we can understand the harm suffered by the Inuit when global warming renders their traditional culture unsustainable without trying to estimate the intrinsic value of that culture.

${ }^{13}$ It is therefore not what Moore calls an 'efficiency' argument - see her powerful critique of such arguments in Moore (1998), pp. 147-9.

${ }^{14}$ I have defended this assumption in Miller (2007), ch. 7. See also Meisels (2009), pp. 101-2 for a defence of the claim that certain forms of land use have universal value.

15 'Under normal circumstances' because we can conceive of extreme cases where the human rights of outsiders - for food and so forth - could only be met by increasing the universal value of a particular piece of territory (say by introducing new farming methods), in which case it would not be enough for the group that currently occupies it to say that their activities were not diminishing its value. They would have either to reform their practices or give way to incomers who could use the land more productively.

16 Think of a person who at $\mathrm{T} 1$ joins a co-operatively run firm that improves its productive process and thereby increases its income over time. Each year 5\% of the employees leave and are replaced by others. Consider now the income that this person is able to enjoy at T2 (income that is fairly distributed among those belonging to the firm at that moment) as a result of the developments that have occurred between $\mathrm{T} 1$ and $\mathrm{T} 2$. What should we say about the fairness of this, given that the improvements are the combined work of successive teams of employees? Not perhaps that the person deserves, in a positive sense, all of that income; but nor can one say that the income is undeserved. What fairer way of allocating the income at $\mathrm{T} 2$ is there than to distribute it among the members of the firm at T2?

${ }^{17}$ Such wronging could occur either because the excluded group could demonstrate a clear historical title to the territory, or because it could show that its members' basic needs for subsistence etc could only feasibly be met by being granted access, thereby generating a human rights claim.

${ }^{18}$ For another example consider the interesting case of the forest of Bialowicza, as described in Schama (2004), ch. 1. This ancient forest plays a central role in the national imagination of Poland, especially through the poetry of the patriotic writer 
Adam Mickiewicz, but at different historical times it has been included within the boundaries of Lithuania, Germany and Russia; it is now once more Polish territory.

${ }^{19}$ In this context, it is interesting to note that both national courts and international bodies such as the U.N. Human Rights Committee have been willing to adjudicate claims to land rights made by indigenous groups by asking whether such rights are indeed necessary to protect the group's culturally distinct way of life - in the process not shirking questions about group identity. See Eisenberg (forthcoming) and Xanthaki (2008), ch.6.

${ }^{20}$ Hillel Steiner has defended this proposal. See Steiner (1994), pp. 269-73; Steiner (1996), p. 146; Steiner (2005), p. 36.

${ }^{21}$ See my discussion in Miller (2007), ch. 3.

${ }^{22}$ I do not mean to deny that rich societies may have redistributive obligations to the global poor, but only that using natural resource holdings as the tax basis for such transfers is misguided.

${ }^{23}$ For some practical examples, including Easter Island, the Galapagos and the Valley of the Nile, see McVeigh (2009).

${ }^{24}$ I have developed this point in Miller (2008).

\section{References}

Baldwin, T. (1992) 'The Territorial State', in H. Gross and R. Harrison (eds.), Jurisprudence: Cambridge Essays. Oxford: Clarendon Press, pp. 207-30.

Buchanan, A. (2004) Justice, Legitimacy and Self-Determination: Moral Foundations for International Law. Oxford: Oxford University Press.

Eisenberg, A. (forthcoming) 'Domestic and International Norms for Assessing Indigenous Identity' in A. Eisenberg and W. Kymlicka (eds.), Institutions and Identities. Vancouver: University of British Columbia Press.

Hendrix, B. (2008) Ownership, Authority, and Self-Determination. University Park, PA.: Pennsylvania State University Press.

Ivison, D. (2002) Postcolonial Liberalism. Cambridge: Cambridge University Press.

Kolers, A. (2009) Land, Conflict, and Justice: a Political Theory of Territory. Cambridge: Cambridge University Press.

Levy, J. (2000) The Multiculturalism of Fear. Oxford: Oxford University Press.

McVeigh, T. (2009) 'Tourist hordes told to stay away from World Heritage sites by the locals', The Observer, 6 September, available at http://www.guardian.co.uk/environment/2009/sep/06/mass-tourism-environmentaldamage. 
Meisels, T. (2009) Territorial Rights, $2^{\text {nd }}$. ed. Dordrecht: Springer.

Miller, D. (1995) On Nationality. Oxford: Clarendon Press.

Miller, D. (2007) National Responsibility and Global Justice. Oxford: Oxford University Press,

Miller, D. (2008) 'Immigrants, Nations and Citizenship', Journal of Political Philosophy, 16 (4), 371-90.

Miller, D. (2011) 'Property and Territory: Locke, Kant, and Steiner', Journal of Political Philosophy, 19 (1), 90-109.

Moore, M. (1998) 'The Territorial Dimension of Self-Determination' in M. Moore (ed.), National Self-Determination and Secession. Oxford: Oxford University Press, pp. 134-57.

Nine, C. (2008) 'A Lockean Theory of Territory', Political Studies, 56 (1), 148-65.

Pogge, T. (1994) 'An Egalitarian Law of Peoples', Philosophy and Public Affairs, 23 (3), 195-224.

Rawls, J. (1999) The Law of Peoples. Cambridge, Mass.: Harvard University Press.

Schama, S. (2004) Landscape and Memory. London: Harper Collins.

Sidgwick, H. (1908) The Elements of Politics, third edition. London: Macmillan.

Simmons, A. J. (2001) 'On the Territorial Rights of States', Philosophical Issues, 11 (1), 300-26.

Smith, A.D. (1999) 'Nation and Ethnoscape' in Myths and Memories of the Nation. Oxford: Oxford University Press, pp. 149-59.

Steiner, H. (1994) An Essay on Rights. Oxford: Blackwell.

Steiner, H. (1996) 'Territorial Justice' in S. Caney, D. George and P. Jones (eds.), National Rights, International Obligations. Boulder, CO: Westview, pp. 139-48.

Steiner, H. (2005) 'Territorial Justice and Global Redistribution' in G. Brock and H. Brighouse (eds.), The Political Philosophy of Cosmopolitanism. Cambridge: Cambridge University Press, pp. 28-38.

Stilz, A. (2009) 'Why do states have territorial rights?', International Theory, 1 (2), 185-213.

Stilz, A. (2011) 'Nations, States, and Territory', Ethics, 121 (3), 572-601. 
Weber, M. (1970) 'Politics as a Vocation', in H.H. Gerth and C. W. Mills (eds.), From Max Weber. London: Routledge and Kegan Paul, pp. 77-128.

Wenar, L. (2008) 'Property Rights and the Resource Curse', Philosophy and Public Affairs, 36 (1), 2-32.

Xanthaki, A. (2007) Indigenous Rights and United Nations Standards: SelfDetermination, Culture and Land. Cambridge: Cambridge University Press. 